\title{
BMJ Open Psychiatric disorders among men voluntarily in treatment for violent behaviour: a cross-sectional study
}

\author{
Ingunn Rangul Askeland, ${ }^{1,2}$ Trond Heir ${ }^{1,3}$
}

To cite: Askeland IR, Heir T. Psychiatric disorders among men voluntarily in treatment for violent behaviour: a cross-sectional study. BMJ Open 2014;4:e004485. doi:10.1136/bmjopen-2013004485

- Prepublication history for this paper is available online To view these files please visit the journal online (http://dx.doi.org/10.1136/ bmjopen-2013-004485).

Received 15 November 2013 Revised 10 March 2014 Accepted 13 March 2014

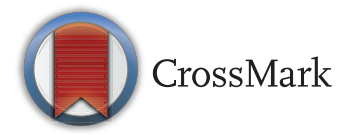

${ }^{1}$ Department of Adults, Norwegian Centre for Violence and Traumatic Stress Studies, Oslo, Norway ${ }^{2}$ Alternative to Violence (ATV), Oslo, Norway ${ }^{3}$ Division of Mental Health, Institute of Clinical Medicine, University of Oslo, Oslo, Norway

\section{Correspondence to} Ingunn Rangul Askeland; i.r.askeland@nkvts.unirand.no

\section{ABSTRACT}

Objectives: Although violent behaviour and psychopathology often co-occur, there has been little research on psychiatric disorders among men in treatment for intimate partner violence (IPV). This study aimed to examine the prevalence of a broad spectrum of psychiatric disorders among men voluntarily attending treatment for IPV.

Setting: 5 clinics for IPV treatment, located in the east, south and west of Norway, participated in the study. In a cross-sectional design, men attending therapy for violence against a partner went through a face-to-face structured diagnostic interview, the Mini International Neuropsychiatric Interview.

Participants: 222 men contacted the clinic during the inclusion period; 12 men did not attend and 13 men were referred to outpatient clinics. Of the 197 men who were offered therapy, 13 did not provide consent to participate in the study, 2 were excluded and 3 men missed the interview.

Results: A total of 179 men participated in the study. The majority were ethnic Norwegians (88\%). A total of $70.9 \%$ of the men fulfilled the diagnostic criteria for at least one ongoing psychiatric disorder. Three categories of disorders stood out with approximately equal prevalences: depressive disorders (40.6\%), anxiety disorders $(38.5 \%)$ including post-traumatic stress disorder (18.4\%) and alcohol/substance abuse $(40.2 \%)$. Antisocial personality disorder was present in approximately 2/10 participants. Comorbidity was high, with nearly half of the men $(48.0 \%)$ assigned two or more diagnoses.

Conclusions: Men voluntarily admitted to treatment for IPV harbour a wide spectrum of psychiatric disorders. Our findings suggest a need for screening procedures for psychiatric disorders as well as adoption of treatment interventions according to different types of psychopathologies and therapeutic needs. Limitations include caution in terms of generalisation to other populations not voluntarily admitted to treatment for IPV, and risk of ignoring symptoms not covered by a clinical structured interview.

For many years, treatment of violent men has been an important means to reduce intimate partner violence (IPV). However, the efficacy

\section{Strengths and limitations of this study}

- Use of a clinical structured interview increases the validity of the study, but includes the risk of ignoring symptoms not covered by the assessment.

- Generalisations to other populations not voluntarily admitted to treatment should be made with caution.

of IPV treatment programmes has been found to be relatively low. ${ }^{1}$ Some researchers have argued that the poor outcomes may be related to how these programmes are constructed. ${ }^{2}$ Reviews of IPV programmes show that the majority rely on sociopolitical theories, typically based on gender resocialisation and cognitive behavioural methods, and the majority of treatment providers do not have an education beyond bachelor level. ${ }^{3}{ }^{4}$ Not including individual factors and psychologically based theories in the programme curriculum could entail that many programmes may not be able to meet this group's various therapeutic needs. ${ }^{5-8}$ The vast majority of IPV treatment programmes are primarily based on an understanding of violence as an abusive form of power and control, emphasising cultural and patriarchal conditions in regard to aetiology and interventions. ${ }^{9}$ A supplementary contribution to the understanding of IPV would be to include information on mental health of men in treatment for IPV.

Violent behaviour has been linked to a variety of mental health symptomatologies such as post-traumatic stress disorder (PTSD),${ }^{10-12}$ personality disorders, ${ }^{13}{ }^{14}$ alcohol problems, ${ }^{15-17}$ anxiety disorders, ${ }^{18}$ depression, ${ }^{19}$ schizophrenia and other psychoses. $^{20}{ }^{21}$ Conversely, severe domestic violence is prevalent among psychiatric inpatients. ${ }^{22}$ It is well known that relative to non-violent men, men who use violence typically display higher levels of substance abuse, ${ }^{23}{ }^{24}$ elevated scores on personality 
pathology ${ }^{25-28}$ and depressive symptoms. ${ }^{29}{ }^{30}$ Of the men in therapy for violent behaviour, those with borderline or antisocial personality traits have been shown to exert more severe physical, psychological and sexual violence. ${ }^{31}$ Furthermore, men with PTSD have been shown to display more aggressive behaviour than those without PTSD. ${ }^{5}$

Despite previous indications of high rates of mental health problems among men in treatment for IPV, there has been little research that includes more accurate indicators of psychiatric disorders. Specifically, there seems to be a lack of studies assessing axis I psychopathology using structured diagnostic interviews. Specific and diagnostic knowledge about these men's mental health may challenge the prevailing aetiological models of partner violence and contribute to further development of our treatment approaches. Given the prior knowledge on these issues, we predicted rather high levels of psychopathology. The purpose of our study was to estimate the prevalence of psychiatric disorders among men voluntarily seeking treatment for IPV, using a structured diagnostic interview.

\section{METHODS}

\section{Participants}

The study population consisted of men voluntarily admitted to a treatment programme for IPV. Of 222 men who contacted a specialised clinic for men using violence against partners during the 1.5 -year period from January 2010 to July 2011, 12 did not come to the clinic and 13 were referred to outpatient clinics due to an acute need for a psychiatric ward or for substance abuse rehabilitation; these men were not offered therapy at the clinic. Of the 197 men who were offered therapy, 13 did not provide consent to participate in the study, 2 were excluded from participation due to language difficulties and 3 missed the interview due to administrative failures. Thus, a total of 179 men participated in the study (90.9\% response rate). All participants had used some type of violence against a current or former partner. Their age ranged from 18 to 72 years (mean age 35.7 years, $\mathrm{SD}=9.9$ ), $87.7 \%$ were ethnic Norwegian, $46.9 \%$ had more than 12 years of education, $72.1 \%$ were employed or studying, $64.2 \%$ were married or cohabitants, $77.1 \%$ had children, $24.6 \%$ had formerly been convicted for a violent crime and $81.9 \%$ had previously received mental healthcare.

\section{Measures}

We used the Mini International Neuropsychiatric Interview (MINI), which is a brief and valid structured diagnostic interview that covers 16 axis I disorders and the axis II antisocial personality disorder according to the Diagnostic and Statistical Manual of Mental Disorders, Fourth Edition (DSM-IV) criteria. ${ }^{32} 33$ With few exceptions, the MINI measures current psychiatric disorders based on symptoms experienced in the previous month. The MINI is a fully validated, more time-efficient alternative to the Structured Clinical Interview for DSM-IV (SCID)-P and Composite International Diagnostic Interview (CIDI) and has good acceptance by patients. ${ }^{34}$ We used the Norwegian version of the MINI, V.5.0.0. ${ }^{35}$ The Norwegian version has been validated in clinical settings and has shown good psychometric properties. ${ }^{35} 36$

Screening for violent behaviour was performed as part of the intake procedure, using a shortened version of the Violence Questionnaire (VQ). ${ }^{37}{ }^{38} \mathrm{VQ}$ includes 40 predefined descriptions of violent behaviour covering seven qualitatively different types of violence (Cronbach's $\alpha$ ranging from $\alpha 0.44$ to $\alpha 0.80$ ). The shortened version included 32 predefined descriptions of violent behaviour covering five qualitatively different types of violent behaviour: physical violence-physical force that inflicts physical harm (punch against body, punch against head, kick, choke, beat up, hit with object, threaten with or use a weapon; such as a knife, firearm or similar object); physically controlling behaviour-physical force that restricts the partner's freedom of action (shake, slap, shove, tug, wrench arm, grab or pull to the ground); property violence (hit walls or the table, throw objects, destroy objects, trash/throw food, smash windows/doors); psychological violence-threatening and humiliating behaviour that restricts the partner's freedom of action or breaks down the partner's sense of self (threats of violence, use threats to get your will, force your will upon her, interrogate, threats of suicide or to kill her, threats of leaving her, threats of violence against children, call her nasty things, make fun of/humiliate her); and sexual violence (forced intercourse, other forced sexual activity, sexual humiliation of partner, used force to have sex after violence). The men were instructed to respond to each of the five different types of violence, indicating how many times they had used some of the described behaviours.

\section{Procedure}

Five treatment clinics were involved in this study; all are affiliated with the Norwegian organisation Alternative to Violence and are located in the east, south and west of Norway. All men were interviewed face to face at their local Alternative to Violence office, with an in-depth session lasting 90-150 min. The interviews were conducted at the intake session by two clinical psychologists who were trained in structured diagnostic interviewing and had substantial clinical experience with treatment of men who use violence. Doubtful cases were discussed by the two clinical psychologists, and in the case of disagreement, a third experienced clinician was consulted.

\section{Ethical considerations}

All participants were verbally informed about the study, presented a written information letter and have given their written consent. 
Table 1 Psychiatric diagnosis in men attending treatment for violent behaviour $(\mathrm{N}=179)$

\begin{tabular}{lrr}
\hline Diagnosis & N & Per cent \\
\hline Major depressive disorder & 57 & 31.8 \\
Dysthymic disorder & $13^{*}$ & 8.8 \\
Manic/hypomanic episode & 8 & 4.5 \\
Panic disorder & 4 & 2.2 \\
Agoraphobia & 25 & 14.0 \\
Generalised anxiety disorder & 9 & 5.0 \\
Social anxiety disorder & 21 & 11.7 \\
Obsessive-compulsive disorder & 17 & 9.5 \\
Post-traumatic stress disorder & 33 & 18.4 \\
Alcohol dependence & 36 & 20.1 \\
Alcohol abuse & 29 & 16.2 \\
Drug dependency & 15 & 8.4 \\
Drug misuse & 5 & 2.8 \\
Psychotic disorder & 3 & 1.7 \\
Anorexia/bulimia & 0 & 0.0 \\
Antisocial personality disorder & 38 & 21.2 \\
Any psychiatric disorder & 127 & 70.9 \\
\hline${ }^{*}$ N=147. & & \\
\end{tabular}

\section{RESULTS}

The majority $(70.9 \%)$ of the men who were offered therapy at the Alternative to Violence clinics and participated in the study fulfilled the diagnostic criteria for at least one current psychiatric disorder. The most prevalent disorder was major depressive disorder, which was present in approximately one-third of the participants (table 1).

Additionally, approximately $10 \%$ of participants qualified for dysthymic disorder, which means that approximately 4/10 participants had a depressive disorder. An equal number of men fulfilled the diagnostic criteria for an anxiety disorder (38.5\%), with PTSD being the most prevalent disorder in this group. Also, an equal number of men fulfilled the criteria for an alcohol or substance abuse disorder (40.2\%). Antisocial personality disorder was present in approximately $2 / 10$ participants. There was a high degree of comorbidity, with approximately half of the men qualifying for more than two diagnoses (table 2).

A considerable number of participants (44.1\%) screened positive for suicidality (table 3 ).

One-quarter of the men reported thinking that it would be better to be dead, without having suicidal plans (a low suicidality score). Approximately $1 / 10$ participants had a high suicidal score that involved specific

Table 2 Number of psychiatric diagnoses in men attending treatment for violent behaviour $(\mathrm{N}=179)$

\begin{tabular}{lll}
\hline Number of diagnoses & $\mathbf{N}$ & Per cent \\
\hline None & 52 & 29.1 \\
One & 41 & 22.9 \\
Two or more & 86 & 48.0 \\
\hline
\end{tabular}

Table 3 Suicidality in men attending treatment for violent behaviour ( $\mathrm{N}=179)$

\begin{tabular}{lll}
\hline Suicidality & N & Per cent \\
\hline No suicidal tendencies & 100 & 55.9 \\
Levels of suicidality & & \\
Low & 47 & 26.3 \\
Moderate & 15 & 8.4 \\
High & 17 & 9.5 \\
\hline
\end{tabular}

suicide plans, an experience of being unable to control suicidal impulses or actual attempts to commit suicide.

\section{DISCUSSION}

This study uncovered a high prevalence of psychiatric morbidity among men who voluntarily attended treatment for violence against a partner. Seven out of 10 participants had at least one psychiatric disorder. Three major groups of disorders stood out, with approximately equal numbers of men in each diagnostic category: depressive disorders, anxiety disorders and alcohol/substance abuse. Comorbidity was high, with nearly half of the men assigned two or more diagnoses.

The prevalence of psychiatric disorders among men in therapy for violent behaviour was considerably higher than that found in the general Norwegian male population. ${ }^{39} 40$ This observation is in line with earlier research showing high levels of mental health problems among violent men. To the best of our knowledge, our study is the first to examine a broad spectrum of psychiatric disorders in men attending therapy for violent behaviour, using a structured diagnostic interview. Previous studies in the field have mainly used self-reporting instruments, which may be less precise in terms of diagnostic accuracy. ${ }^{41}$

The high prevalence of depression in our sample was considerably higher than estimates of probable depressive disorder in American men arrested for domestic violence, whereas the prevalences of PTSD were similar in the current study as in previous work. ${ }^{42}$ Overall, our findings support the notion that men in therapy for IPV suffer from a broad spectrum of psychopathologies. ${ }^{42}$ The high prevalence of alcohol and substance abuse disorders measured here is known from earlier studies. ${ }^{8} 4344$

The association between IPV and mental disorder has yet to be explained. Many men using IPV have experienced childhood abuse and exposure to violence, ${ }^{38} 4546$ factors known to contribute to the development of violent behaviour ${ }^{47} 48$ and to be consistently associated with adult mental disorders. ${ }^{49} 50$ Thus, violent behaviour and psychopathology might be related to long-term effects of growing up in violent homes. ${ }^{51}$ Also, violent behaviour may be more prevalent among individuals with psychiatric diagnoses as a result of mental processes, such as social information processing deficits. ${ }^{11} 52$ Additionally, psychological distress may be caused by violence and its context and consequences. 
The present population consisted of men voluntarily admitted to therapy for violent behaviour. Thus, our findings cannot unconditionally be generalised to populations of men ordered to therapy by a court. Cultural background should also be taken into consideration when interpreting the results. We evaluated 16 axis I DSM-IV disorders that are common in the general population ${ }^{33}$; we cannot rule out the presence of other psychiatric disorders or conditions that may be prevalent among violent men. With the exception of antisocial personality disorder, we did not evaluate axis II disorders. Thus, our study might display a biased picture of the most common psychiatric disorders in this population, personality disorders taken into account. Our findings may be limited to the population of men voluntarily seeking help and should not easily be generalised to violent men in general. Finally, our assessment relied on a single diagnostic instrument, the MINI. Challenges of structured interviews include the risk of ignoring symptoms not covered by the questions and limitations in examining complex issues with dichotomous outcomes.

High prevalence of psychiatric disorders among men attending therapy for violence calls for attention regarding clinical practice for these patients. IPV treatment programmes have, to a limited extent, grown out of psychological knowledge. Treatment of psychiatric disorders is not an integrated part of most IPV programmes. ${ }^{53}$ The majority of IPV programmes in the USA dictate a uniform course of treatment, and some states explicitly forbid the use of more psychological-oriented or mental health-oriented treatment models. ${ }^{9}$ Given the knowledge that the majority of men in treatment for IPV harbour psychiatric disorders that may benefit from therapeutic intervention, it seems rather unethical to not offer this help as an integrated part of therapy. Further, a number of authors have argued that treating psychopathology may have beneficial effects on violent behaviour. ${ }^{54-56}$ This hypothesis has been supported by studies on treatment of alcohol problems, ${ }^{5758}$ but remains to be tested in relation to other psychopathological conditions. ${ }^{59} 60$

Theoretically, violence can be interpreted as exclusively a behavioural, attitudinal or criminal problem. However, violence could also be interpreted as a function of underlying psychological difficulties. The two conditions appear simultaneously, or one after the other, or they may interact in ways that affect the course and prognosis of both conditions. Psychopathology and concurrent violent behaviour call for an intensified approach towards psychiatric disorders as a part of treatment programmes. Regardless of the underlying mechanisms, a high prevalence of psychiatric morbidity suggests the need for diagnostic assessment and treatment in itself.

IPV is a complex phenomenon. Interventions including assessment, knowledge and treatment of psychiatric disorders expand the concept of 'power and control' as the main focus for IPV treatment. Integrating relevant psychological issues in treatment of IPV may generate new requirements for educating and training IPV treatment providers. Further, this may be particularly important, enabling the development of treatment programmes designed to meet each individual's therapeutic needs and thereby enhancing the probability of better programme outcome.

Acknowledgements The authors would like to thank the staff members at Alternative to Violence and the Norwegian centre for violence and traumatic stress studies for their support in conducting the study. They would also like to thank Bente Loemo for interviewing participants, and the rest of the research group, Odd Arne Tjersland and John-Filip Strandmoen for their support, advice and critical review of the manuscript.

Contributors IRA collected the data and wrote the draft. IRA and TH contributed to the conception and design of the study, interpretation of the data and revised and approved the final version of the draft.

Funding The study was carried out as part of the Alternative to Violence Therapy Research Programme, which was funded by the Ministry of Health and Care Services, Ministry of Children, Equality and Social Inclusion, Ministry of Justice and Public Security and the Directorate of Health and Social Welfare in Norway.

Competing interests None.

Ethics approval Regional Committees for Medical and Health Research Ethics.

Provenance and peer review Not commissioned; externally peer reviewed.

Data sharing statement No additional data are available.

Open Access This is an Open Access article distributed in accordance with the Creative Commons Attribution Non Commercial (CC BY-NC 3.0) license, which permits others to distribute, remix, adapt, build upon this work noncommercially, and license their derivative works on different terms, provided the original work is properly cited and the use is non-commercial. See: http:// creativecommons.org/licenses/by-nc/3.0/

\section{REFERENCES}

1. Babcock JC, Green CE, Robie C. Does batterers' treatment work? A meta-analytic review of domestic violence treatment. Clin Psychol Rev 2004;23:1023-53.

2. Sonkin D, Liebert D. The assessment of court-mandated perpetrators of domestic violence. J Aggression Maltreat Trauma 2003;6:3-36.

3. Maiuro RD, Hagar TS, Lin H, et al. Are current state standards for domestic violence perpetrator treatment adequately informed by research? A question of questions. J Aggression Maltreat Trauma 2001;5:21-44.

4. Saunders DG. Group interventions for men who batter: a summary of program descriptions and research. Violence Vict 2008;23:156-72.

5. Rosenbaum A, Leisring PA. Beyond power and control: towards an understanding of partner abusive men. J Comp Fam Stud 2003;34:7-22.

6. Price BJ, Rosenbaum A. Batterer intervention programs: a report from the field. Violence Vict 2009;24:757-70.

7. Stuart GL, Temple JR, Moore TM. Improving batterer intervention programs through theory-based research. JAMA 2007;298:560-2.

8. Tolman RM, Bennett LW. A review of quantitative research on men who batter. J Interpers Violence 1990;5:87-118.

9. Maiuro RD, Eberle JA. State standards for domestic violence perpetrator treatment: current status, trends, and recommendations. Violence Vict 2008;23:133-55.

10. Bell KM, Orcutt HK. Posttraumatic stress disorder and male-perpetrated intimate partner violence. JAMA 2009;5:562-4.

11. Taft CT, Schumm JA, Marshall AD, et al. Family-of-origin maltreatment, PTSD symptoms, social information processing deficits, and relationship abuse perpetration. J Abnorm Psychol 2008;117:637-46.

12. Taft CT, Walling SM, Howard JM, et al. Trauma, PTSD and partner violence in military families. In: MacDermid Wadsworth S, Riggs D. eds. U.S. military families under stress. New York, NY: Springer, 2010:195-211.

13. Johnson JG, Cohen P, Smailes E, et al. Adolescent personality disorders associated with violence and criminal behavior during 
adolescence and early adulthood. Am J Psychiatry

2000;157:1406-12

14. Stone $\mathrm{MH}$. Violent crimes and their relationship to personality disorders. Pers Ment Health 2007;1:138-53.

15. Coid J, Yang M, Roberts A, et al. Violence and psychiatric morbidity in the national household population of Britain: public health implications. Br J Psychiatry 2006;189:12-19.

16. Keller PS, El-Sheikh M, Keiley M, et al. Longitudinal relations between marital aggression and alcohol problems. Psychol Addict Behav 2009;23:2-13.

17. Thompson MP, Kingree JB. The role of alcohol use in intimate partner violence. Violence Vict 2004;19:63-73.

18. Danielson KK, Moffitt TE, Caspi A, et al. Comorbidity between abuse of an adult and DSM-III-R mental disorders: evidence from an epidemiological study. Am J Psychiatry 1998;155:131-3.

19. Pan HS, Neidig PH, O'Leary KD. Predicting mild and severe husband-to-wife physical aggression. J Consult Clin Psychol 1994;62:975-81.

20. Fazel S, Gulati G, Linsell L, et al. Schizophrenia and violence: systematic review and meta-analysis. PLoS Med 2009;6:e1000120.

21. Soyka M. Substance misuse, psychiatric disorder and violent and disturbed behavior. Br J Psychiatry 2000;176:345-50.

22. Howard LM, Trevillion $\mathrm{K}$, Khalifeh $\mathrm{H}$, et al. Domestic violence and severe psychiatric disorders: prevalence and interventions. Psychol Med 2010;40:881-93.

23. Hastings JE, Hamberger LK. Personality characteristics of spouse abusers: a controlled comparison. Violence Vict 1988;3:31-48.

24. Moore TM, Stuart GL, Meehan JC, et al. Drug abuse and aggression between intimate partners: a meta-analytic review. Clin Psychol Rev 2008;28:247-74.

25. Beasley R, Stoltenberg CD. Personality characteristics of male spouse abusers. Clin Psychol Res Pract 1992;23:310-17.

26. Dutton DG. Behavioral and affective correlates of Borderline Personality Organization in wife assaulters. Int $J$ Law Psychiatry 1994;17:265-77.

27. Else L, Wonderlich SAM, Beatty WW, et al. Personality characteristics of men who physically abuse women. Hosp Community Psychiatry 1993;44:54-8.

28. Murphy CM, Meyer S, O'Leary KD. Family of origin violence and MCMI-II psychopathology among partner assaultive men. Violence Vict 1993;8:165-76.

29. Hamberger K, Hastings JE. Personality correlates of men who batter and non-violent men: some continuities and discontinuities. J Fam Violence 1991;6:131-47.

30. Maiuro RD, Cahn TS, Vitaliano PP, et al. Anger, hostility and depression in domestically violent versus generally assaultive men and nonviolent control subjects. J Consult Clin Psychol 1988;56:17-23.

31. Holtzworth-Munroe A, Meehan J, Herron K, et al. Do subtypes of maritally violent men continue to differ over time? J Consult Clin Psychol 2003;71:728-40.

32. Sheehan DV, Lecrubier $\mathrm{Y}$, Sheehan $\mathrm{KH}$, et al. The validity of the Mini International Neuropsychiatric Interview (MINI) according to the SCID-P and its reliability. Eur Psychiatry 1997;12:232-41.

33. Sheehan DV, Lecrubier Y, Sheehan KH, et al. The Mini-Internationa Neuropsychiatric Interview (M.I.N.I): the development and validation of structured diagnostic psychiatric interview for DSM-IV and ICD-10. J Clin Psychiatry 1998;59:22-33.

34. Pinninti NR, Madison H, Musser E, et al. MINI International Neuropsychiatric Schedule: clinical utility and patient acceptance. Eur Psychiatry 2003;18:361-4.

35. Leiknes KA, Leganger S, Malt EA, et al. MINI International Neuropsychiatric Interview (1992-2009). MINI Internasjonal neuropsykiatrisk intervju, Norwegian version 5.0.0 and 6.0.0. Norway/Norwegian-Mapi Research Institute.

36. Mordal J, Gundersen O, Bramness JG. Norwegian version of the mini-international neuropsychiatric interview: feasibility, acceptability and test-retest reliability in an acute psychiatric ward. Eur Psychiatry 2010;25:172-7.

37. Skjørten K. Voldsbilder i hverdagen. Om menns forståelse av kvinnemishandling [images of violence in everyday life: on men's understanding of violence against women]. Oslo, Norway: Pax Forlag, 1994
38. Askeland IR, Evang A, Heir T. Association of violence against partner and former victim experiences: a sample of clients voluntarily attending therapy. J Interpers Violence 2011;26:1095-110.

39. Kringlen E, Torgersen S, Cramer V. A Norwegian psychiatric epidemiological study. Am J Psychiatry 2001;158:1091-8.

40. Sandanger I, Nygård JF, Ingebrigtsen $\mathrm{G}$, et al. Prevalence, incidence and age at onset of psychiatric disorders in Norway. Soc Psychiatry Psychiatr Epidemiol 1999;34:570-9.

41. Shorey RC, Elmquist J, Ninnemann A, et al. The association between intimate partner violence perpetration, victimization, and mental health among women arrested for domestic violence. Partner Abuse 2012;3:3-21.

42. Shorey RC, Febres J, Brasfield $\mathrm{H}$, et al. The prevalence of mental health problems in men arrested for domestic violence. J Fam Violence 2012;27:741-8.

43. Gondolf EW. Characteristics of court-mandated batterers in four cities: diversity and dichotomies. Violence Against Women 1999;5:1277-93.

44. Stuart GL, Moore TM, Kahler CW, et al. Substance abuse and relationship violence among men court-referred to batterers intervention programs. Subst Abus 2003;24:107-22.

45. Ehrensaft MK, Cohen $\mathrm{P}$, Brown J, et al. Intergenerational transmission of partner violence: a 20-year prospective study J Consult Clin Psychol 2003;71:741-53.

46. Gil-Gonzalez D, Vives-Cases C, Ruiz MT, et al. Childhood experience of violence in perpetrators as a risk factor of intimate partner violence: a systematic review. J Public Health 2008;30:14-22

47. Herrenkohl TI, Mason WA, Kosterman R, et al. Pathways from physical childhood abuse to partner violence in young adulthood Violence Vict 2004;19:123-36.

48. Dutton D. The batterer: a psychological profile. New York, NY: Basic Books, Harper Collins Publisher, Inc, 1995.

49. Green JG, McLaughlin KA, Berglund PA, et al. Childhood adversities and adult psychiatric disorders in the national comorbidity survey replication I, associations with first onset of DSM-IV disorders. Arch Gen Psychiatry 2010;67:113-23.

50. McLaughlin KA, Green JG, Gruber MJ, et al. Childhood adversities and adult psychiatric disorders in the national comorbidity survey replication II, associations with persistence of DSM-IV disorders. Arch Gen Psychiatry 2010;67:124-32.

51. Elbogen EB, Johnson SC. The intricate link between violence and mental disorder. Results from the National Epidemiologic Survey on Alcohol and Related Conditions. Arch Gen Psychiatry 2009;66:152-61.

52. Chemtob CM, Novaco RW, Hamada RS, et al. Anger regulation deficits in combat-related posttraumatic stress disorder. J Trauma Stress 1997;10:17-36.

53. Rothman EF, Butchart A, Cerda M. Interventions with men who batter: a global perspective. Geneva, Switzerland: World Health Organization, 2003. http://www.who.int/violence_injury_prevention/ publications/violence/intervening/en/

54. Dutton DG, Sonkin DJ. Intimate violence: contemporary treatment innovations. Binghampton, NY: Haworth Press, 2003.

55. Orcutt HK, King LA, King DW. Male-perpetrated violence among Vietnam veteran couples: relationships with veteran's early life characteristics, trauma history, and PTSD symptomatology. J Trauma Stress 2003;16:381-90.

56. Taft CT, Macdonald A, Monson CM, et al. 'Strength at home' group intervention for military populations engaging in intimate partner violence: pilot findings. J Fam Violence 2013;28:225-31.

57. O'Farrell TJ, Murphy CM, Stephan SH, et al. Partner violence before and after couples-based alcoholism treatment for male alcoholic patients: the role of treatment involvement and abstinence. $J$ Consult Clin Psychol 2004;72:202-17.

58. Stuart GL, Meehan J, Moore TM, et al. Examining a conceptua framework of intimate partner violence in men and women arrested for domestic violence. J Stud Alcohol 2006;67:102-12.

59. Heru AM. Effective treatments for patients with intimate partner violence. Adv Psychiatr Treat 2007;13:376-83.

60. Taft CT, Schumm J, Orazem RJ, et al. Examining the link between posttraumatic stress disorder symptoms and dating aggression perpetration. Violence Vict 2010;25:456-69. 